\title{
Pyrometer Device
}

National Cancer Institute

\section{Source}

National Cancer Institute. Pyrometer Device. NCI Thesaurus. Code C50063.

A device designed to measure high temperatures, such as those in a furnace. 